\title{
TEMAS PROBLEMLERİNDE SONLU ELEMANLAR YÖNTEMİNİN DOĞRULUĞUNUN İNCELENMESİ
}

\author{
Murat YAYLACI, Cemalettin TERZi ${ }^{*}$
}

Recep Tayyip Erdoğan Üniversitesi, Mühendislik Fakültesi, İnşaat Mühendisliği Bölümü, Rize, Türkiye

\begin{tabular}{ll}
\hline Anahtar Kelimeler & Öz \\
\hline Temas Mekaniği, & Bu çalışmada, ANSYS ve ABAQUS yazılımları kullanılarak rijit bir panç ile bir elastik \\
Temas Mesafeleri, & yarım düzlem üzerine bağlanmış birbirine bağlı iki tabakanın simetrik temas \\
Temas Gerilmeleri, & problemi dikkate alınmıştır. Tabakalar farklı elastik sabit ve yüksekliklere sahiptir. \\
Sonlu Elemanlar Yöntemi. & Dış yük üst elastik tabakaya rijit bir panç vasıtasıyla uygulanmıştır. Bu problem iki \\
& elastik tabaka arasında ve rijit panç arasındaki temasın sürtünmesiz olduğu ve \\
& yerçekimi kuvvetinin etkisinin ihmal edildiği varsayımıyla çözülmüștür. Sayısal \\
& uygulamalar sonlu eleman yöntemine dayanan ANSYS ve ABAQUS yazılımları ile \\
& çözülmüştür. Temas uzunlukları ve temas gerilmeleri farklı yük, malzeme ve \\
& geometri parametrelerine göre elde edildi ve sonuçlar tablo ve grafikler halinde \\
& verilmiştir. Bu sonuçlar literatürdeki ilgili temas probleminin analitik sonuçlarıyla \\
& karşıștırılarak doğrulanmıştır.
\end{tabular}

\section{INVESTIGATION OF THE ACCURACY OF FINITE ELEMENTS METHOD IN CONTACT} PROBLEMS

Keywords
Contact Mechanics,
Contact Length,
Contact Stress,
Finite Element Method.

\begin{abstract}
In this study, the symmetrical contact problem of two bonded layers resting on an elastic half plane with a rigid punch had been considered according to Finite Element Method using ANSYS and ABAQUS software. These elastic layers have different elastic constants and heights. The external load had been applied to the upper elastic layer by means of a rigid stamp. This problem had been solved under the assumptions that the contact between two elastic layers, and between the rigid stamp are frictionless, the effect of gravity force had been neglected. Numerical practices had been performed by ANSYS and ABAQUS software based on FEM. The contact length and contact stress had been obtained according to different parameters of load, material and geometry and results had been presented in tables and graphics. These results had been confirmed by comparing the analytical results of the related contact problem in the literature.
\end{abstract}

\footnotetext{
Alıntı / Cite

Yaylacı M., Terzi C., (2018). Temas Problemlerinde Sonlu Elemanlar Yönteminin Doğruluğunun İncelenmesi, Journal of Engineering Sciences and Design, 6(3), 511- 519.
}

\begin{tabular}{l|l|l}
\hline Yazar Kimliği / Author ID (ORCID Number) & \multicolumn{3}{|l}{ Makale Süreci / Article Process } \\
\hline M. Yaylacı, 0000-0003-0407-1685 & Başvuru Tarihi /Submission Date & 16.03 .2018 \\
C. Terzi, 0000-0002-8169-5814 & Revizyon Tarihi / Revision Date & 28.08 .2018 \\
& Kabul Tarihi / Accepted Date & 13.09 .2018 \\
& Yayım Tarihi / Published Date & 27.09 .2018 \\
\hline
\end{tabular}

\section{Giriş}

Son 20 yılda temas problemine odaklanan araştırma ve çabaların çok fazla olması bu konunun önemini göstermektedir. Temas mekaniği, mekanik ve inşaat mühendisliğindeki endüstriyel uygulamalarda önemli bir konudur. Metal şekillendirme işlemleri, sondaj

\footnotetext{
* ilgili yazar / Corresponding author: cemalettin.terzi@erdogan.edu.tr
} 
problemleri, rulmanlar, çarpma analizleri, otomobil lastikleri veya elektronik cihazların soğutulması, frenler, debriyajlar, içten yanmalı motorlar, menteșeler ve contalar temas problem uygulamalarının geniş yelpazesinin bazılarıdır. Diğer uygulamalar insan eklemleri, implantlar veya dişlerin göz önüne alındığı biyomekanik ile ilgilidir.

Geçmişte birçok araştırmacı temas problemlerini teknik öneminden dolayı araştırmıştır. İnşaat mühendisliği alanında temas problemi ile ilgili birçok konu vardır. Temasın olmadığı bir durumla karşılaşmak oldukça zordur. Hertz (1881) temel çalışmasından bu yana 100 yıldan fazla geçmesine rağmen temas problem hala büyük bir ilgi görmektedir. Hertz (1896) tarafından eğri yüzeyli iki gövdenin birbirine basınç uyguladığında ortaya çıkan basınç alanındaki gerilme dağılımı belirlenmiştir. 0 zamandan beri genelde sonsuz boyutlu basit geometriler içeren birçok temas problemi analitik olarak çözülmüștür. Bu problemlerin çoğu literatürde (Gladwell, 1980; Johnson, 1985; Özşahin vd., 2007; Çömez vd., 2004; Öner ve Birinci, 2014) bulunabilir.

Değişik türde temas problemleri birçok araştırmacı tarafından sayısal ve analitik olarak 40 yıldan daha fazla süredir çalışılmıştır. Temas problemleri ile alakalı analitik ve sayısal çalışmalar literatürde geniş bir alan kaplamaktadır. Long ve Wang (2013) eksenel simetrik temas problemlerinde yüzey gerilmesinin etkisini araştırmışlardır. Yang (2013) farklı malzemeli tabakaların temas problemlerinin çözümleri üzerine çalışmıştır. Chidlow ve Teodorescu (2013) tarafından rijit bir panç altında homojen olmayan elastik bir malzemenin sürtünmesiz iki boyutlu temas problemi incelenmiştir. Düzlem elastisite teorisinin temas probleminde sürtünme ve așınma dikkate alınarak Soldatenkov (2013) tarafından incelenmiștir. Gun ve Gao (2014) homojen olmayan, izotropik ve doğrusal elastik fonksiyonel olarak derecelendirilmiş malzemelerin sürtünmeli sürekli temas problemleri için bir kuadratik sınır eleman problem önermiştir. Analitik yaklaşımların kısıtlayıcı olması ve bilgisayar teknolojisinin ilerlemesi temas problemlerinde sayısal metodların gelişmesine neden olmuştur. Günümüzde temas mekaniği problemlerinin çözümünde kullanılan sayısal yöntemlerden biri sonlu elemanlar metodudur. Sonlu elemanlar alanında yapılan temel çalışmalar (Chan ve Tuba, 1971; Fredricksson, 1976; Okamoto ve Nakazawa, 1979; Oden ve Pires, 1984; Bathe ve Chaudhary, 1985; Klarbring ve Björkman, 1992) şeklinde verilebilir.

Schwarzer vd. (1995) küresel Hertz temas problemini, yük altında tabakalı malzemelerde gerilme dağılımını açıklamak için bir analitik model ile bir sonlu eleman modelini karşılaştırmışlardır. Zhu (1995) sürtünmeli elastoplastik temas problemleri için sonlu eleman temelli matematiksel programlama üzerinde çalışmıştır. Belgacem vd. (1998) tarafından temas problemleri sonlu elemanlar yöntemi ile incelenmiştir. Guyot vd. (2000) sürtünmeli temas problemlerinin incelenmesi için sonlu elemanlar ve sınır elemanlar metodlarının birleștirilmesini incelemişlerdir. Solberg vd. (2007) temas problemlerinin sonlu eleman çözümleri için basit iki geçişli çift formülasyon üzerinde çalışmışlardır. Oysu (2007) sonlu elemanlar ve sinır elemanlar yöntemlerinde ă̆ yenileme uygulayarak temas problemlerinde gerilme analizlerini ele almıştır. Zhang vd. (2012) çok sayıda malzemenin iki boyutlu elastik-plastik temas analizleri için bir sonlu eleman modeli önermişlerdir. Birinci vd. (2015) tarafından temas problemlerinin sayısal ve analitik çözümlerinin karşılaştırmalı çalışmaları yürütülmüştür.

$\mathrm{Bu}$ çalışma ayrılmalı temas problemlerinin sonlu elemanlar yöntemi yardımıyla çözümü ile ilgilidir. $\mathrm{Bu}$ çalışmada farklı elastik sabit ve yüksekliklere sahip iki sonsuz elastik tabaka ve bir rijit pançın düzlemsel simetrik ayrılmalı temas problemi araştırılmıștır. Dıș yükler üst elastik tabakaya rijit bir panç vasıtasıyla Şekil 1.'de görüldüğü şekilde uygulanmıştır. Temas yüzeylerinin sürtünmesiz olduğu ve yerçekimi kuvvetinin ihmal edildiği varsayılmıștır (Adıbelli, 2010). Problem sonlu eleman yöntemi temelli ANSYS (2013) ve ABAQUS (2017) programlarında modellenmiş ve analiz edilmiștir. Temas yüzeyleri ve temas gerilmeleri için elde edilen sonuçlar farklı değerlere göre elde edilmiştir. Bu değerler grafik ve tablolarla gösterilmiştir. Sayısal sonuçlar literatürdeki analitik sonuçlar ile karşılaştırılarak doğrulanmıștır.

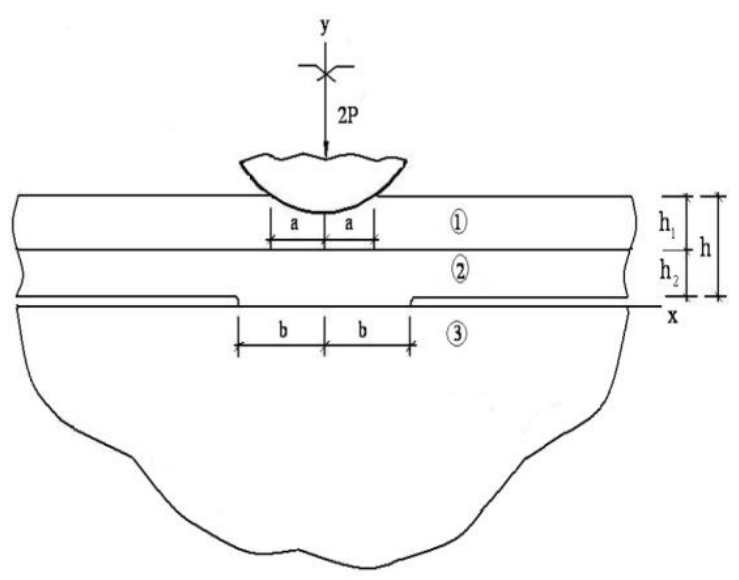

Şekil 1. Temas probleminin geometrisi

\section{Temas Problemlerinde Sonlu Elemanlar Yöntemi}


Sonlu elemanlar metodu temas problemlerinin çözümünde etkili bir araçtır. Bu metod, elemanların gerçek bir geometri ile birbiri arasındaki ilişkisini, malzemelerin fiziksel ve mekanik özelliklerini, karışık sınır şartı durumlarını tanımlamaya imkan sağlar. Bu tip hesaplamaların yapıldığı ANSYS, NASTRAN, ALGOR, ABAQUS gibi birçok program bulunmaktadır. $\mathrm{Bu}$ çalışmada temas problemlerinin çözümünde ANSYS ve ABAQUS programları kullanılmıştır.

$\mathrm{Bu}$ tip problemler genel olarak temas problemleri olarak adlandırılır. Elemanlar arasındaki temas, yük aktarma metotlarından biridir. Bu tür bir yük aktarma tekniği iki ya da daha fazla temas yüzeyi arasındaki ilişkinin yapısına bağlıdır. Temas durumunun doğrudan incelenmesi ve kesin bir şekilde değerlerin ölçülmesi oldukça zordur. Temas problemi temas gerilmelerini oluşturan elemanların davranışının, malzeme özelliklerine bağlı olmasından dolayı karmaşıktır.

Temas problemlerini sonlu elemanlar yöntemiyle modellemek oldukça zor olmasına rağmen bu yöntem uzun yıllardır temas problemlerinin çözümünde kullanılmaktadır. Günümüzde bu yöntem ürünlerin tasarımı ve geliștirilmesi sürecinde maliyetlerin azaltılması için endüstri alanında da yer buldu.

\section{Sonlu Eleman Modeli}

Ayrılmalı temas probleminin iki boyutlu modeli ANSYS ve ABAQUS sonlu eleman yazllımlarıyla modellenmiştir. Temas analizleri sayesinde elde edilen değerler teorik değerlerle karşılaştırılarak sonuçların tutarlı olduğu gösterilmiştir. Bunların hepsi model ve sınır şartlarının doğruluğunu ve yük altında temas problemlerinin optimum tasarımı için bilimsel bir temel sağladığını ortaya koydu.

Temas problemini çözmek için ANSYS ve ABAQUS ticari sonlu eleman paket programları kullanılmıştır. Problem iki boyutlu temas problemi olarak düşünülmüş ve tabakaların malzemeleri elastik ve izotropik olarak varsayılmıştır. Göz önünde bulundurulan sistem geometri, malzeme özellikleri ve yükleme açısından simetrik olarak ele alınmıştır. Simetriklik avantajından faydalanılarak yalnızca problem geometrisinin yarısı modellenmiștir. Sonlu eleman yöntemindeki sayısal çözümde veri olarak bazı malzeme ve geometrik özelliklerine ihtiyaç vardır. Analizde, geometrik özellik olarak $L=50 \mathrm{~m}$ (x doğrultusundaki tabaka uzunluğu), $\mathrm{h}_{1}=1 \mathrm{~m} \quad(\mathrm{y}$ doğrultusunda alttaki tabakanın kalınlığı), yük olarak $P=120000 \mathrm{~N}$ ve malzeme özellikleri $E_{1}=3 \cdot 10^{4} \mathrm{MPa}$ ,$v_{2}=v_{1}=0.25 \quad$ seçilmiştir. $\quad\left(G_{1} /\left(P / h_{1}\right)\right),\left(R / h_{1}\right)$, $m=\left(G_{2} / G_{1}\right)$ ve $n=\left(G_{3} / G_{2}\right)$ oranları gibi seçilen diğer parametreler analitik çözümden elde edilen boyutsuz değerler ile uyumludur. Burada $G$ değeri kayma modülünü, $R$ değeri panç yarıçapını ifade etmektedir. Geometri ve uygulanan yük Şekil.2.'de gösterilmektedir.

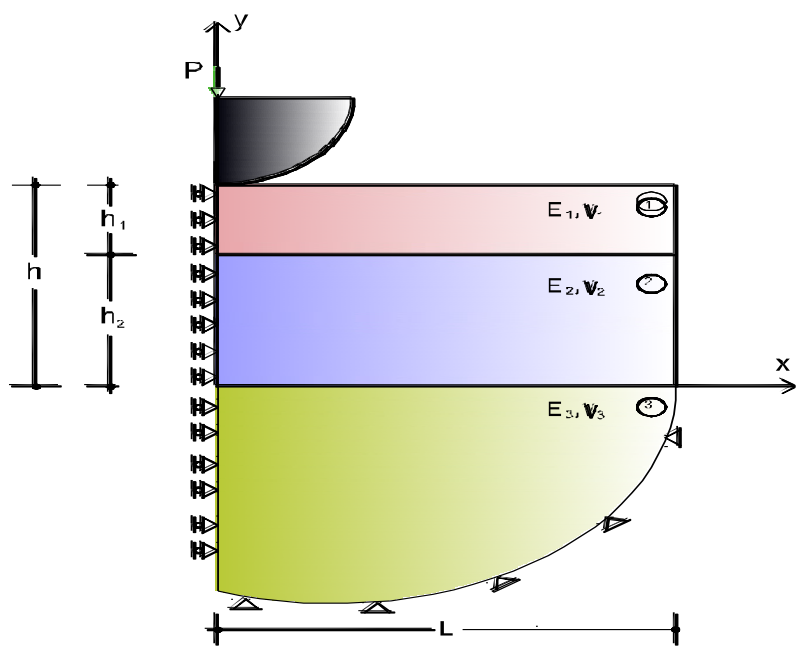

Şekil 2. Analiz edilen problemin geometrisi

Temas problemlerinde iki sınır durumu vardır. Bunlardan ilki temas yüzeyi diğeri ise hedef yüzeyidir. Seçilen yüzey-yüzey temas durumu bu problem için uygundur. Yüzey-yüzey temasının analiz adımları başlıca şu şekildedir: (1) İki boyutlu geometrik modelin oluşturulması; (2) malzeme özelliklerinin belirlenmesi; (3) ağ yapısının oluşturulması; (4) temas çiftinin tanımlanması; (5) gerekli sınır şartları ve yükleme adımlarının uygulanması; (6) çözüm seçeneklerinin tanımlanması; (7) temas probleminin analiz edilmesi; (8) analiz sonuçlarının gözden geçirilmesi.

Problemin ANSYS ve ABAQUS programinda modellenen sonlu eleman modelinin analiz öncesi görünüşleri Şekil. 3 ve Şekil. 4'te, elemanların analiz sonrası deformasyona uğramış görünüşleri Şekil. 5 ve Şekil. 6'da görülmektedir.

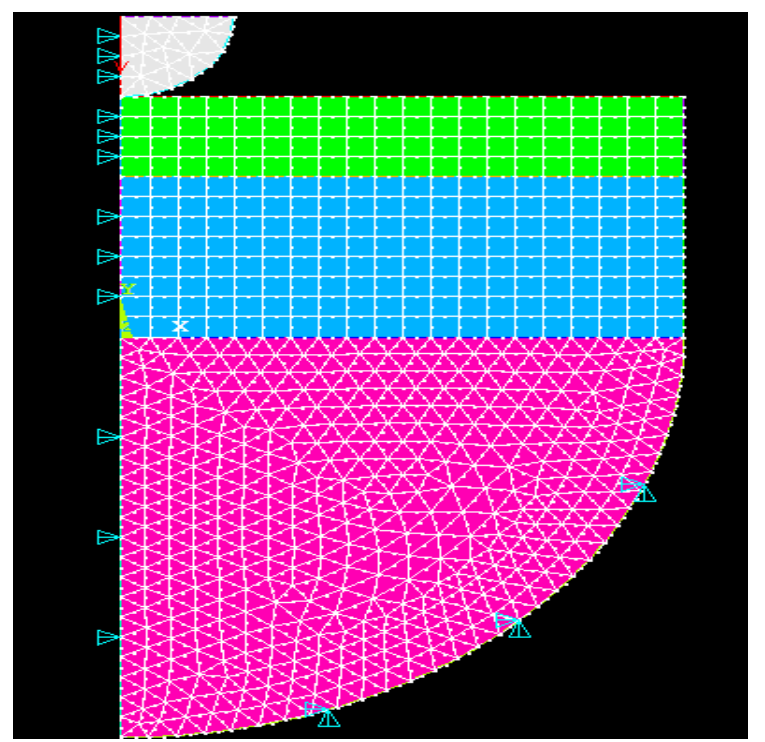

Şekil 3. ANSYS programında yapılan sonlu eleman ağ yapısı görünümü 


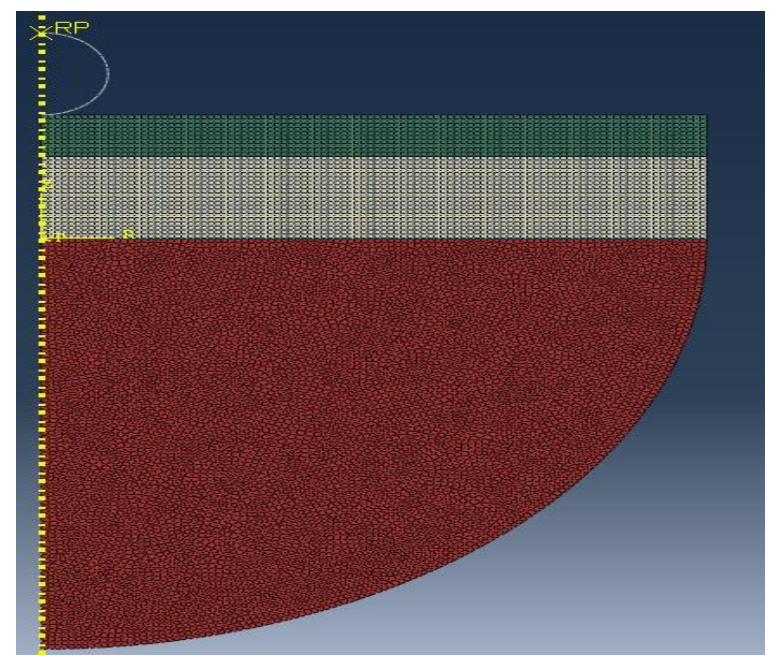

Şekil 4. ABAQUS programında yaplan sonlu eleman ağ yapısı görünümü

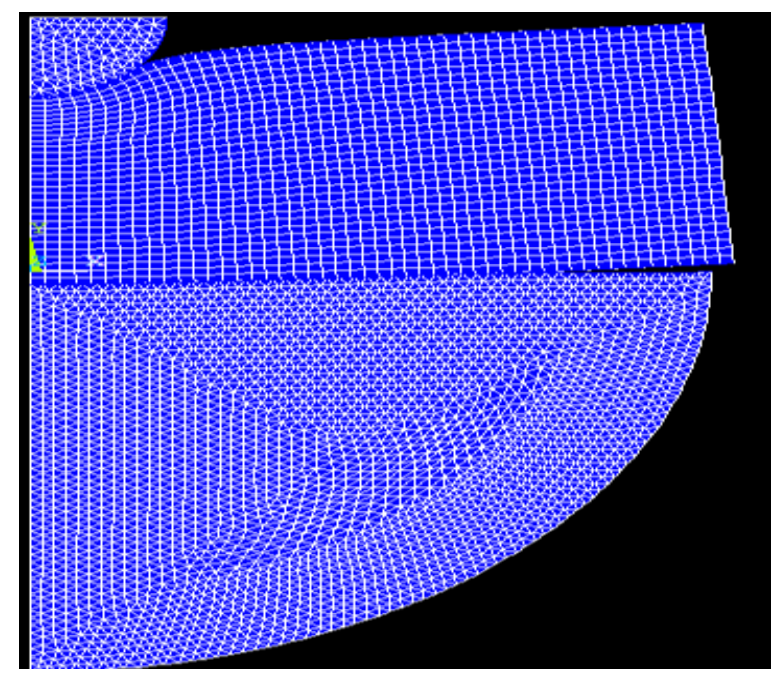

Şekil 5. ANSYS programında analiz sonrası görünüş

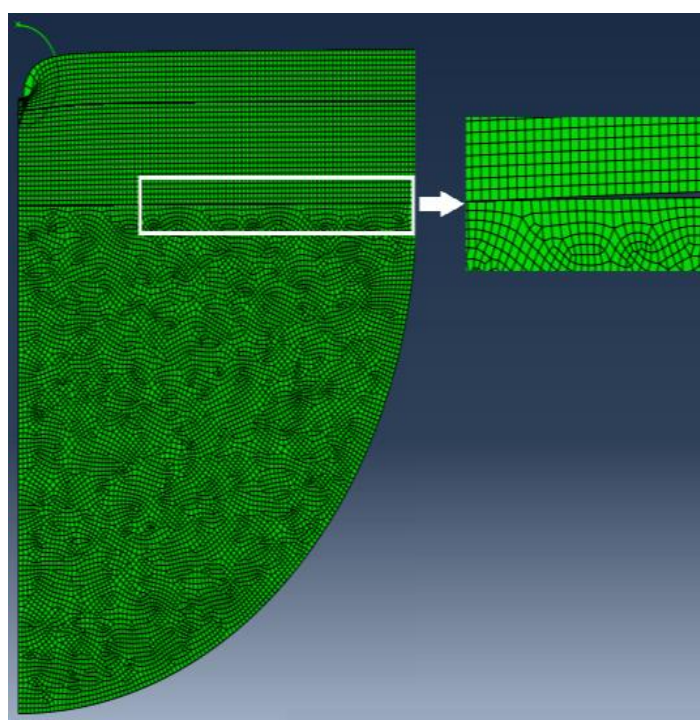

Şekil 6. ABAQUS programında analiz sonrası görünüş

\section{4. Çözümlerin Karşılaştırılması}

Sonlu eleman analizden elde edilen sonuçlarının doğruluğunun kontrolü için en ikna edici yol sonlu eleman sonuçlarını bilinen analitik çözüm sonuçları ile karşılaştırmaktır. ANSYS ve ABAQUS programları ile yapılan sonlu eleman analizleri sırasında çeşitli değerler için elde edilen temas mesafeleri $\left(a / h_{1}, b / h_{1}\right)$ ve temas gerilmeleri $\left(P_{1} /\left(P / h_{1}\right)\right)$, $\left(P_{2} /\left(P / h_{1}\right)\right)$ bulunmuştur. ANSYS ve ABAQUS programlarının çalıștırılması sırasında $n, m, R / h_{1}$ ve $G_{1} /\left(P / h_{1}\right)$ gibi çeșitli boyutsuz değerler için elde edilen sonuçlar Tablo 1-4 ve Şekil 7-10 da görülmektedir. Sunulan sonuçlar literatürde (Adıbelli, 2010) bulunan değerlerle karşılaştırılmıștır. Așağıda verilen sonuçlardan da görüldüğü gibi, elde edilen sonuçlar gerçek temas problemlerini çözmek için kullanılan iyi bir yaklașık metod olan sonlu elemanlar metodu analizinden elde edilen değerler ile bilinen teorik sonuçların arasında iyi bir uyum olduğunu göstermektedir.

Bütün şekillerde görüldüğü gibi çalıșmada sunulmuş olan sonlu eleman metodu analizi (ABAQUS ve ANSYS) sonuçlarından elde edilen temas mesafeleri ve temas gerilmelerinin literatürdeki (Adıbelli, 2010) sonuçlara çok yakın olduğu görülmektedir. Sonlu eleman ve analitik çözümünden elde edilen boyutsuz gerilmeler açısından da sonuçların uyumlu olduğu tüm şekillerde görülmektedir. 
Tablo 1. Panç yarıçapına bağlı olarak yükün değişimine göre temas uzunlukları $\left(a / h_{1}, b / h_{1}\right)$ $\left(h_{2} / h_{1}=2, G_{2} / G_{1}=2, G_{3} / G_{2}=2\right)$

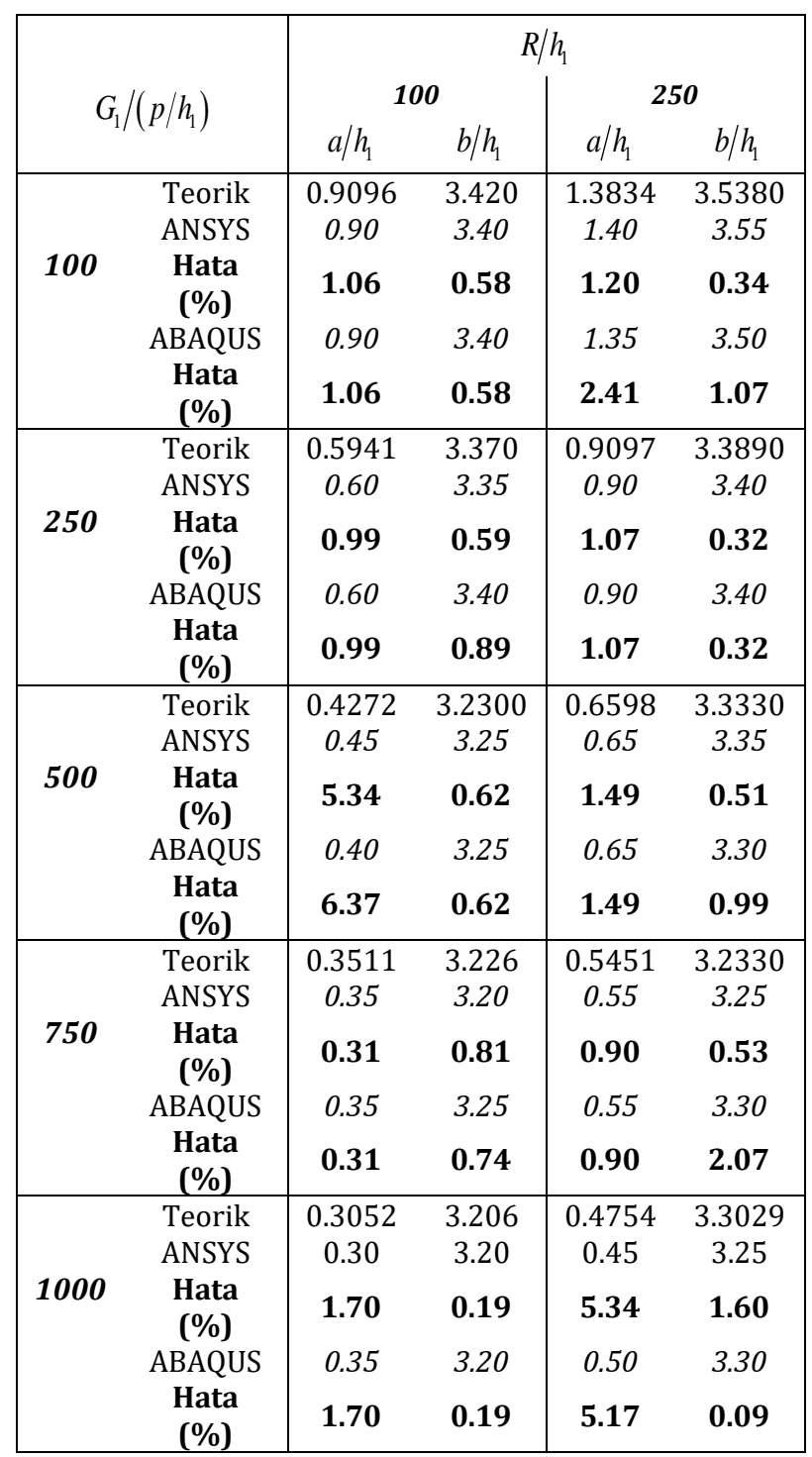

Tablo 2. Panç yarıçapına bağlı olarak yükün değişimine göre temas uzunlukları $\left(a / h_{1}, b / h_{1}\right)$ $\left(h_{2} / h_{1}=2, G_{2} / G_{1}=2, G_{3} / G_{2}=2\right)$

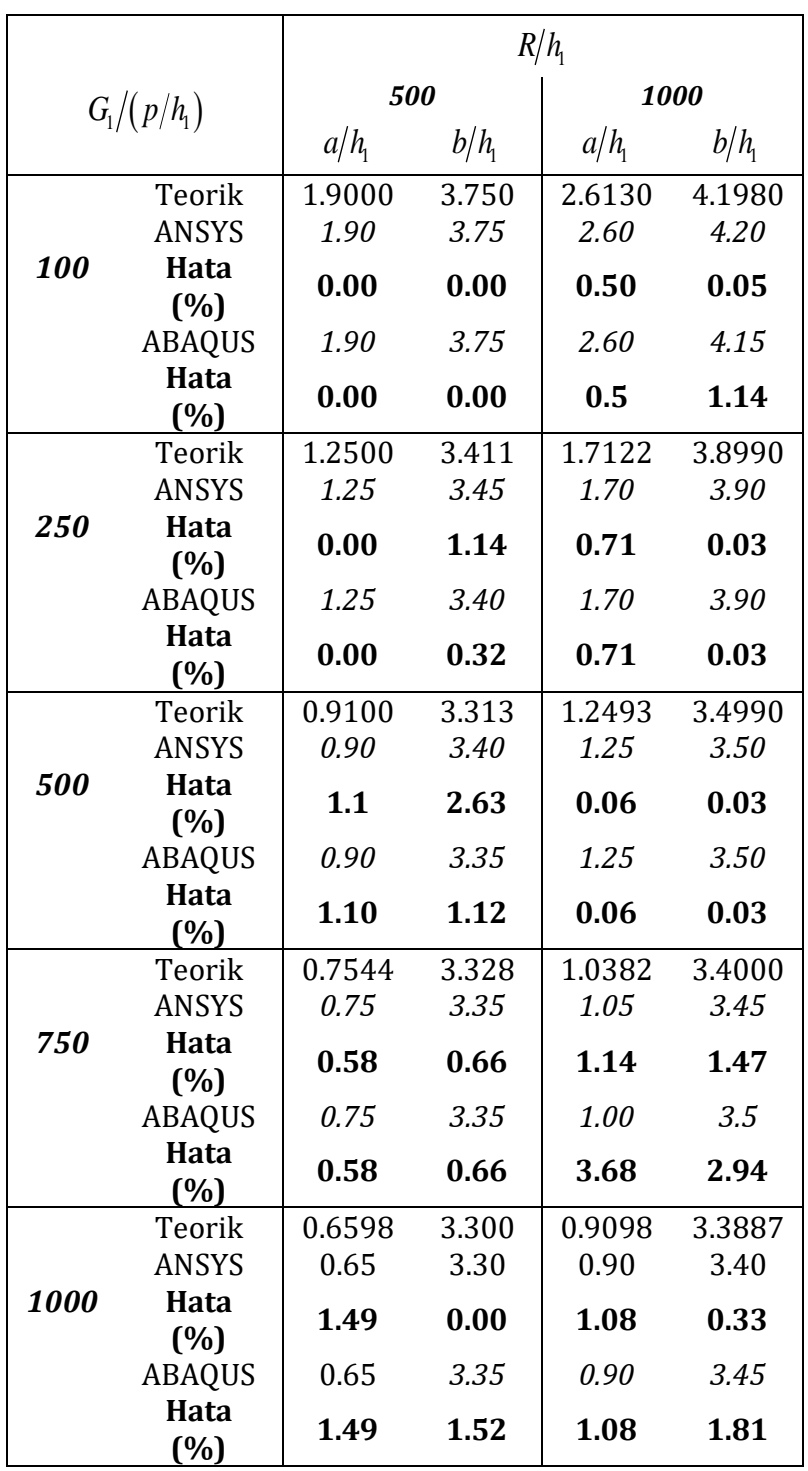


Tablo 3. Kayma modülleri oranının değişimine göre temas uzunlukları $\left(a / h_{1}, b / h_{1}\right)$

$\left(h_{2} / h_{1}=2, R / h_{1}=500, G_{1} /\left(P / h_{1}\right)\right)$

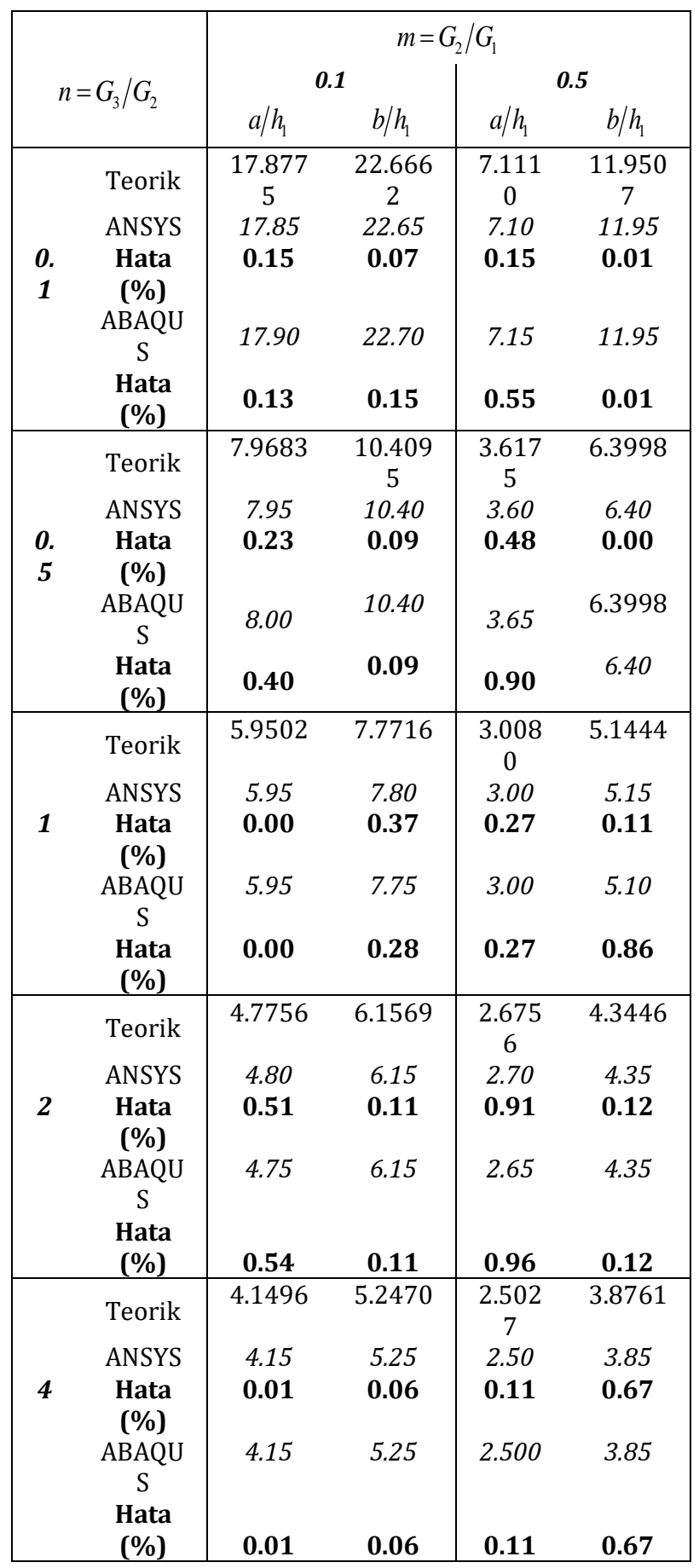

Tablo 4. Kayma modülleri oranının değişimine göre temas uzunlukları $\left(a / h_{1}, b / h_{1}\right)$ $\left(h_{2} / h_{1}=2, R / h_{1}=500, G_{1} /\left(P / h_{1}\right)\right)$

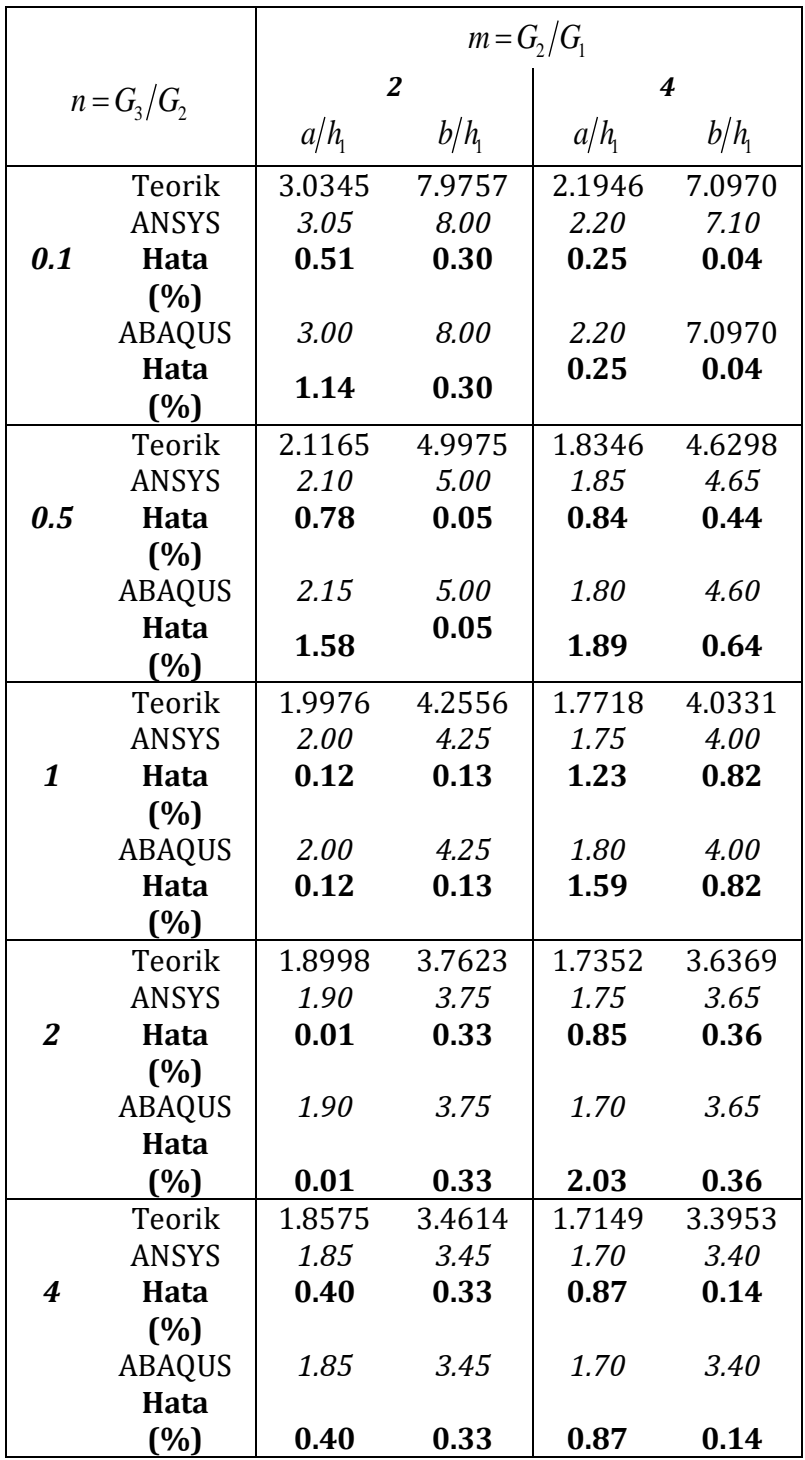

Yük $\left(G_{1} /\left(P / h_{1}\right)\right)$ ve panç yarıçap $\left(R / h_{1}\right)$ değerlerinin değişimi ile ANSYS ve ABAQUS çözümlerinden elde edilen, panç üst tabaka arasındaki $\left(a / h_{1}\right)$ ve alt tabaka yarım düzlem arasındaki $\left(b / h_{1}\right)$ temas mesafeleri Tablo 1 ve Tablo 2'de teorik sonuçlarla birlikte verilmektedir.

Tablo 3 ve Tablo 4'de ise tabakaların kayma modülleri oranı $(m)$ ve alt tabaka yarım düzlem kayma modülleri oranının $(n)$ değerleri değiștirilerek bu çalıșmadan elden edilen temas mesafeleri teorik sonuçlarla karşılaştırılarak hata oranlarıyla birlikte verilmektedir. 


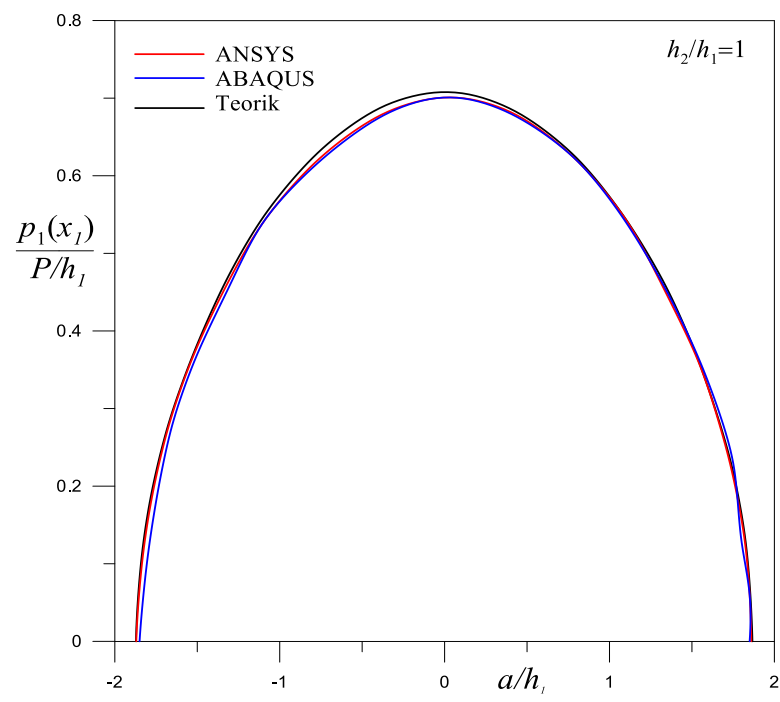

Şekil 7. Tabakaların yükseklikleri oranlarına bağlı olarak $y=0$ da temas gerilmesi

$m=2, n=2, G_{1} /\left(P / h_{1}\right)=100, \kappa_{1}=\kappa_{2}=\kappa_{3}=2, R / h_{1}=500$

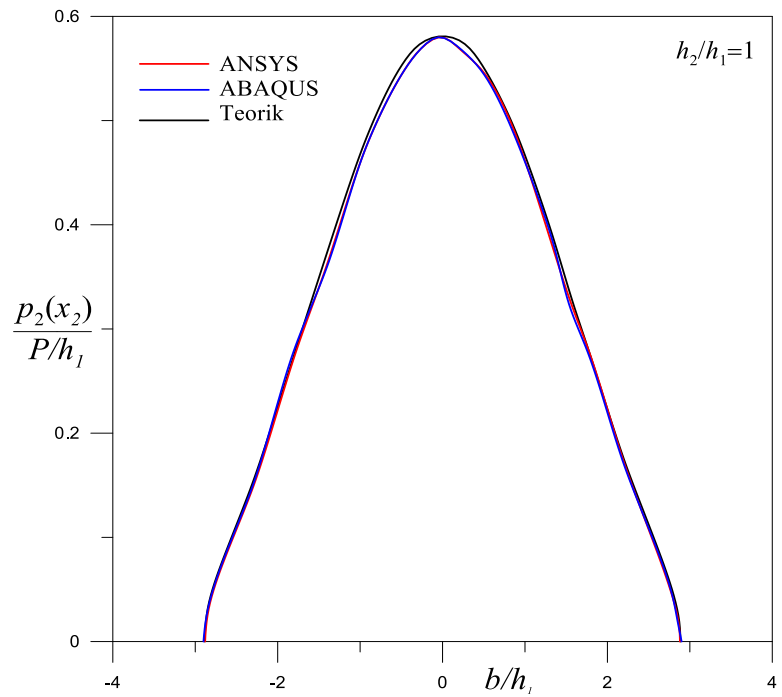

Şekil 8. Tabakaların yükseklikleri oranlarına bağlı olarak $y=-h$ da temas gerilmesi

$m=2, n=2, G_{1} /\left(P / h_{1}\right)=100, \kappa_{1}=\kappa_{2}=\kappa_{3}=2, R / h_{1}=500$

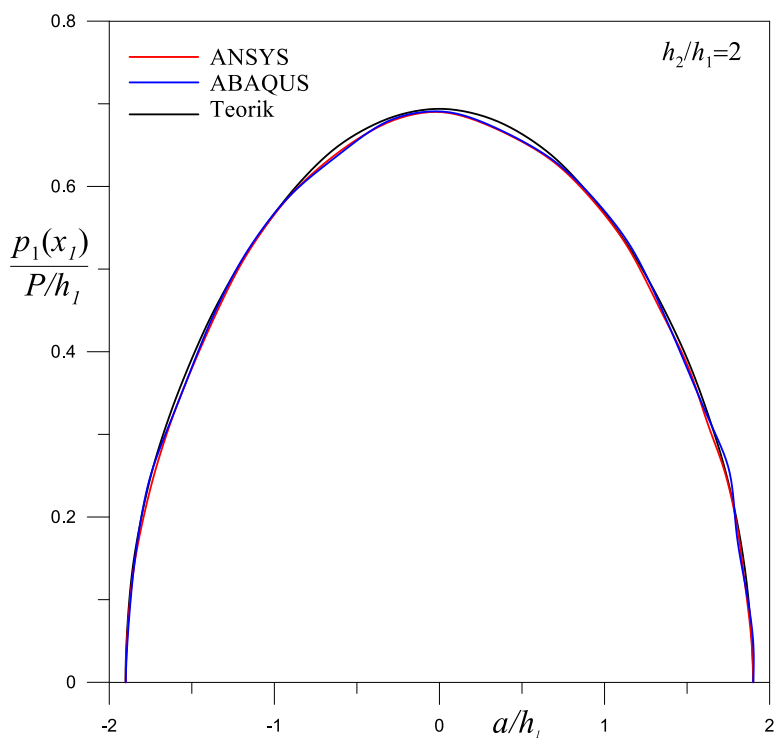

Şekil 9. Tabakaların yükseklikleri oranlarına bağlı olarak $y=0$ da temas gerilmesi

$m=2, n=2, G_{1} /\left(P / h_{1}\right)=100, \kappa_{1}=\kappa_{2}=\kappa_{3}=2, R / h_{1}=500$

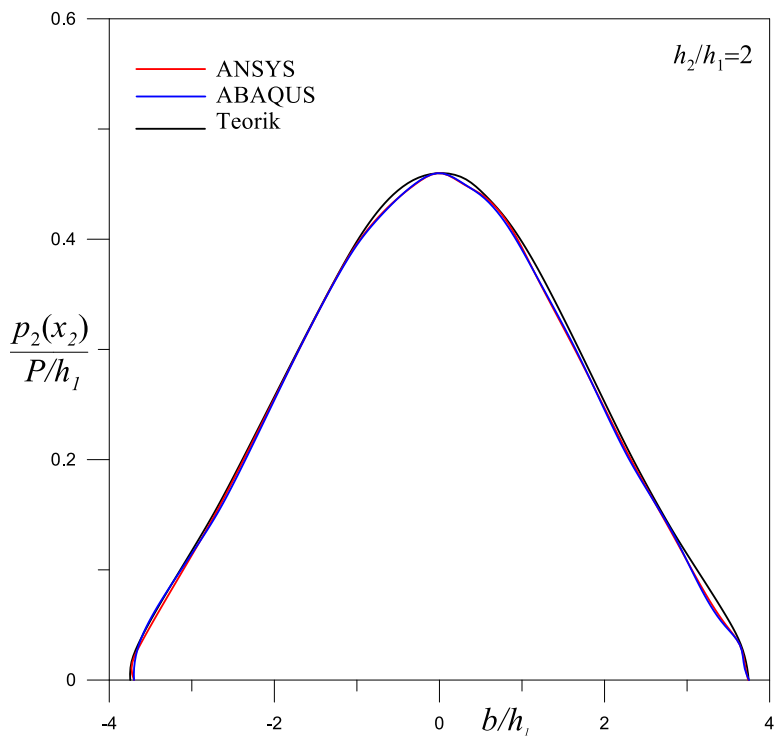

Şekil 10. Tabakaların yükseklikleri oranlarına bağlı olarak $y=-h$ da temas gerilmesi

$m=2, n=2, G_{1} /\left(P / h_{1}\right)=100, \kappa_{1}=\kappa_{2}=\kappa_{3}=2, R / h_{1}=500$

Şekil 7 ve Şekil 8'de tabakaların yüksekliği eşit olması durumunda sırasıyla panç üst tabaka $\left(\left(P_{1}(x) /\left(P / h_{1}\right)\right)\right.$ ve alt tabaka yarım düzlem arasındaki $\left(P_{2}(x) /\left(P / h_{1}\right)\right)$ temas gerilme dağılımları görülmektedir. $h_{2} / h_{1}=2$ olması durumunda temas gerilmeleri Şekil 9 ve Şekil 10 'da sunulmaktadır.

Tablo ve șekillerden ANSYS ve ABAQUS analiz sonuçlarının teorik sonuçlara çok yakın olduğu ve hata oranlarının çok düşük olduğu görülmektedir. 


\section{Sonuç}

$\mathrm{Bu}$ çalışmanın amacı temas problemlerinde sonlu elemanlar metodu (SEM) ve analitik metot kullanılarak elde edilen sonuçlar arasında karşllaştırma yapmaktır. Sonuçlar gösterdi ki sonlu elemanlar metodu ile analitik metot arasında iyi bir uyum vardır.

$\mathrm{Bu}$ çalışma bir yarım düzlem ve iki elastik tabaka arasındaki temas probleminde temas mesafeleri ve temas gerilmelerini hesaplamak için bir sonlu eleman metodu analizini sunmaktadır. Sonlu eleman metodundan elde edilen sonuçlar temas problemlerinde temas mesafeleri ve temas gerilmelerinin hesaplanmasında metodun çok etkili ve doğru olduğunu göstermektedir. Sonlu elemanlar yöntemi kullanılarak temas problemlerinde temas mesafeleri ve temas gerilmeleri teorik sonuçlara yakın bir şekilde elde edilebileceği görülmektedir.

Analitik sonuçlarla nümerik sonuçlar karşılaştırıldığında nümerik sonuçların çok doğru sonuçlar verdiği görülmektedir. Bu yüzden sayısal yaklaşım çok iyi sonuçlar vermesi sebebiyle temas problemlerinin çözümünde kullanılabilir. Sayısal sonuçlar analitik sonuçlardan çok az oranda sapmaya sahiptir.

\section{Teşekkür}

$\mathrm{Bu}$ çalışma Recep Tayyip Erdoğan Üniversitesi Bilimsel Araştırma Projeleri Koordinasyon Birimi tarafından FBA-2016-659 nolu proje kapsamında desteklenmiştir. Yazarlar, desteklerinden dolayı Recep Tayyip Erdoğan Üniversitesi Bilimsel Araştırma Projeleri Koordinasyon Birimine teşekkürlerini sunar.

\section{Conflict of Interest / Çıkar Çatışması}

Yazarlar tarafından herhangi bir çıkar çatışması beyan edilmemiștir.

No conflict of interest was declared by the authors.

\section{Kaynaklar}

ABAQUS. 2017. ABAQUS/Standard: User's Manual. Dassault Systèmes Simulia, Johnston, RI

Adıbelli, H., 2010. Elastik Yarım Düzleme Oturan Simetrik Yüklü Yapıșık Çift Tabakada Değme Ve Çatlak Problemi. Doktora Tezi, Karadeniz Teknik Üniversitesi, Trabzon.

ANSYS. 2013. Swanson Analysis Systems Inc., Houston, PA, USA.

Bathe, K.J., Chaudhary, A., 1985. A Solution Method for Planar and Axisymmetric Contact Problems. International Journal for Numerical Methods in Engineering, 21, 65-88.
Belgacem, F.B., Hild, P., Laborde, P., 1998. The Mortar Finite Element Method for Contact Problems. Mathematical Computational, 28(4-8), 263-271.

Birinci, A., Adıyaman, G., Yaylacı, M., Öner, E., 2015. Analysis of Continuous and Discontinuous Cases of a Contact Problem Using Analytical Method and FEM. Latin American Journal of Solids And Structures, 12(9), 1771-1789.

Chan, S.K., Tuba, I.S., 1971. A Finite Element Method for Contact Problems of Solid Bodies-I. Theory and Validation. International Journal Mechanical Science, 13, 615-625.

Chidlow, S.J., Teodorescu, M., 2013 Two-Dimensional Contact Mechanics Problems Involving Inhomogeneously Elastic Solids Split Into Three Distinct Layers. International Journal of Engineering Science, 70, 102-123.

Çömez, İ., Birinci, A., and Erdöl, R., 2004. Double Receding Contact Problem for a Rigid Stamp and Two Elastic Layers. European Journal of Mechanics A/Solids, 23, 301-309.

Fredriksson, B., 1976. Finite Element Solution of Surface Nonlinearities in Structural Mechanics With Special Emphasis to Contact and Fracture Mechanics Problems. Computational Structural, 6, 281-290.

Gladwell, G.M.L., 1980. Contact Problems in the Classical Theory of Elasticity, Sijthoff and Nordhoff.

Gun, H., Gao, X.W., 2014. Analysis of Frictional Contact Problems for Functionally Graded Materials Using BEM. Engineering Analysis Boundary Element, 38, $1-7$.

Guyot, N., Kosior, F., Maurice, G., 2000. Coupling of Finite Elements and Boundary Elements Methods for Study of the Frictional Contact Problem. Computational Methods Applied Mechanical Engineering, 181(1-3), 147-159.

Hertz, H., 1881. Über die Berührung fester elastischer Körper, Journal für die reine und angewandte Mathematik,92, 156-171.

Hertz, H., 1896. Miscellaneous Papers on the Contact o1 Elastic Solids. Translation by D. E. Jones. McMillan, London.

Johnson, K.L., 1985. Contact Mechanics, Cambridge University Press, Cambridge, U.K.

Klarbring, A., Orkman, G., 1992. Solution of Large Displacement Contact Problems with Friction Using Newton's Method for Generalized Equations. International Journal. Numerical Methods in Engineering, 34, 249-269.

Long, J.M., Wang, G.F., 2013. Effects of Surface Tension on Axisymmetric Hertzian Contact Problem. Mechanics of Materials, 56, 65-70.

Oden, J.T., Pires, E.B., 1984. Algorithms and Numerical Results for Finite Element Approximations of 
Contact Problems with Non-Classical Friction Laws. Computational Structure, 19, 137-147.

Okamoto, N., Nakazawa, M., 1979. Finite Element Incremental Contact Analysis with Various Frictional Conditions. International Journal for Numerical Methods in Engineering, 14, 337-357.

Öner, E., Birinci, A., 2014. Continuous Contact Problem for Two Elastic Layers Resting on an Elastic HalfInfinite Plane. Journal of Mechanics of Materials and Structures, 9 (1), 105-119.

Oysu, C., 2007. Finite Element and Boundary Element Contact Stress analysis with Remeshing Technique. Applied Mathematical Model, 31, 2744-2753.

Özşahin, T.S., Kahya, V., Birinci, A., Cakiroğlu, A.O., 2007 Contact Problem for an Elastic Layered Composite Resting on Rigid Flat Supports. International Journal of Computational and Mathematical Sciences, 1, 154-159.

Schwarzer, N., Djabella, H., Richter, F., Arnell, R.D., 1995. Comparison Between Analytical and FEM Calculations for The Contact Problem of Spherical Indenters on Layered Materials, Thin Solid Films, $270,279-282$.

Solberg, J.M., Jones, R.E., Papadopoulos, P., 2007. A Family of Simple Two-Pass Dual Formulations for the Finite Element Solution of Contact Problems. Comput. Methods Applied Mechanical Engineering 196 (4-6), 782-802.

Soldatenkov, I.A., 2013. The Periodic Contact Problem of the Plane Theory Of Elasticity. Taking Friction, Wear and Adhesion into Account. Pmm-J. Appl. Mathematical Mechanic, 77, 245-255.

Yang, Y.Y., 2013. Solutions of Dissimilar Material Contact Problems Engineering Fracture Mechanics, 100, 92-107.

Zhang, H.W., Xie, Z.Q., Chen, B.S., Xing, H.L., 2012. A Finite Element Model for 2D Elastic-Plastic Contact Analysis of Multiple Cosserat Materials. European Journal of Mechanics A/Solids. 31, 139-151.

Zhu, C., 1995. A Finite Element-mathematical Programming Method for Elastoplastic Contact Problems with Friction. Finite Elem. Anal. Des. 20 (4), 273-282. 